\author{
Г.В. Худов ${ }^{1}$, О.М. Маковейчук ${ }^{2}$, I.М. Бутко ${ }^{3}$, I.А. Хижняк ${ }^{1}$ \\ ${ }^{1}$ Харківський національний університет Повітряних Сил ім. I. Кожедуба, Харків \\ ${ }^{2}$ Харківський начіональний університет радіоелектроніки, Харків \\ ${ }^{3}$ Державне підприємство “Центр Державного земельного кадастру”, Київ
}

\title{
МОДЕЛЬ ПРОГНОЗУВАННЯ ГЕОПРОСТОРОВИХ ДАНИХ В СИСТЕМАХ ОБРОБКИ ГЕОПРОСТОРОВОЇ ІНФОРМАЦІЇ
}

Предметом дослідження в статті є прогнозування геопросторових даних в системах обробки геопросторової інформації. Метою статті є розробка моделі прогнозування геопросторових даних в системах обробки геопросторової інформачії. Удосконалено модель прогнозування даних, яка представляє собою адаптивну селективну модель на базі ансамблю інтегрованих моделей авторегресії-ковзного середнього $\{\operatorname{ARIMA}(p, d, q)\}$ різних порядків. При иьому в якості критерія селекиії використовується мінімум суми квадратів відхилень для попередніх прогнозів, що забезпечує точність та робастність прогнозу $і$ дає можливість приймати на його основі обтрунтовані управлінські рішення. Напрямком подальших досліджень є проведення верифікаиії отриманого прогнозу.

Ключові слова: геопросторові дані, обробка геопросторової інформащії, модель прогнозування, ARIMA модель, АRМА модель, часовий ряд.

\section{Вступ}

Постановка проблеми. На сьогоднішній день статистичний аналіз даних є обов'язковим етапом системи управління на усіх іiі рівнях. В системах обробки геопросторової інформації статистичні моделі використовуються для діагностики стану об'єктів управління та при прогнозуванні та прийнятті обгрунтованих та оптимальних управлінських рішень на основі геопросторових даних [1].

Передбачити та віднайти оптимальне управлінське рішення в системах обробки геопросторової інформації в умовах невизначеності $є$ складною задачею [1]. Інструментом мінімізації невизначеності $€$ прогнозування, а науково обгрунтований результат про можливі управлінські рішення на основі геопросторових даних є прогнозом.

Науковими способами прогнозування є моделювання та аналіз часових рядів. На сьогоднішній день задача прогнозування часових рядів $є$ дуже актуальною в багатьох областях людської діяльності.

Аналіз останніх досліджень і публікацій. Проведено велику кількість досліджень щодо можливості прогнозування фінансових часових рядів [26]. На протязі довгого періоду часу використовували фундаментальний аналіз, тобто вивчення основних чинників, які сприяють добробуту економіки в цілому, промислових секторів й окремих компаній. Але такий підхід має наступні недоліки. По-перше, необхідність великих затрат часу, по-друге, такий аналіз обов'язково супроводжується суб'єктивністю аналітика [2].

Тому в останній час багато спеціалістів в обла- сті фінансів для розв'язання цієї задачі використовують методи аналізу даних, зокрема прогнозування часових рядів [2].

Тому взявши до уваги досвід спеціалістів та проведений аналіз останніх досліджень в області фінансів для прогнозування геопросторових даних в системах обробки геопросторової інформації будемо використовувати прогнозування часових рядів, в якому задача зводиться до того, щоб, маючи певну кількість спостережень за деяким явищем, побудувати прогноз щодо майбутньої поведінки цього процесу [2].

Моделі прогнозування часових рядів поділяються на дві групи, а саме, моделі предметної області та моделі часових рядів [2]. Моделі предметної області - математичні моделі прогнозування, для побудови яких використовують закони предметної області, в яких використовують функціональні залежності, властиві конкретній предметній області.

Моделі часових рядів - математичні моделі прогнозування, які мають знайти залежність майбутнього значення від минулого всередині самого процесу і на цій залежності обчислити прогноз. Ці моделі $є$ універсальними для різних предметних областей.

В свою чергу, моделі часових рядів можна поділити на статистичні та структурні. У статистичних моделях залежність майбутнього значення від минулого задається у вигляді деякого рівняння [3]. До статистичних моделей відносяться регресійні моделі, авторегресійні моделі, моделі на основі експоненціального згладжування та інші.

В роботі [2] проведений аналіз статистичних моделей та визначені їх переваги, а саме, однако- 
вість аналізу і проектування; простота моделювання та математичних обчислень; відсутність жорстких обмежень на довжину тренувальної послідовності. Недоліком є залежність якості прогнозу від параметрів згладжування [3].

Багато досліджень в області прогнозування часових рядів присвячено питанню побудови нейронних мереж для цього. Штучні нейронні мережі представляють собою систему поєднаних та взаємодіючих штучних нейронів. Кожен штучний нейрон такої нейронної мережі має справу тільки із сигналами, які він періодично посилає іншим штучним нейронам та сигналами, які він періодично отримує. 3'єднані такі локально прості штучні нейрони в досить велику нейронну мережу разом здатні виконувати доволі складні завдання [5].

Здатності нейронної мережі до прогнозування безпосередньо випливають з іiі здатності до узагальнення і виділення прихованих залежностей між вхідними та вихідними даними. Після навчання нейронна мережа здатна передбачити майбутнє значення якоїсь послідовності на основі декількох попередніх значень i/aбо деяких існуючих чинників.

Перевагами $є$ масштабованість, можливість моделювання нелінійних процесів, висока адаптивність та різноманітність сфер застосування [2]. Недоліками - складність вибору архітектури та алгоритму навчання, відсутність прозорості і неможливість аналізу отриманих результатів, ресурсомісткість процесу навчання [5].

Перспективним напрямком наукових досліджень вважають прогнозування з використання марковських моделей. Ідея застосування марковських моделей до прогнозування часових рядів обгрунтована на припущенні, що в основі коливань часового ряду лежить деякий марковський випадковий процес [4]. Марковським називається випадковий процес, який має таку властивість: уся передісторія процесу повністю зосереджена у теперішньому стані, який тільки один впливає на майбутнє, і не важливо, як процес розвивався у минулому [2].

У середині 90-х років минулого століття був розроблений принципово новий і досить потужний клас алгоритмів для прогнозування часових рядів. Більшу частину роботи $з$ дослідження методології та перевірки моделей було Г.Е.П. Боксом та Г.М. Дженкінсом [9]. Вони запропоновали цілу ієрархію алгоритмів, найвідомішим з яких є алгоритм ARIMA, який вбудований практично в будь-який спеціалізований пакет для прогнозування.

На сьогоднішній день існує декілька відомих модифікацій моделей ARIMA [6]. Це:

SARIMA -модель, яка дозволяє ураховувати сезонну компоненту;

ARCH - модель з умовною гетероскедастичністю;
GARCH - узагальнена модель моделі з умовною гетероскедастичністю ARCH;

IGARCH - інтегрована модель моделі GARCH; AGARCH - асиметрична модель моделі GARCH;

TGARCH - порогова модель моделі GARCH;

ARMAX - модель, яка дає можливість враховувати вплив зовнішніх чинників;

та ін. [6].

Основними перевагами моделей прогнозування ARIMA $€$ [7]:

- простота та прозорість моделювання;

- однаковість аналізу й проектування та різноманітність сфер застосування;

Але й існують недоліки, а саме:

- неможливість моделювання нелінійних залежностей;

- трудомісткість та ресурсомісткість ідентифікації найбільш відповідної моделі.

Беручи до уваги усі переваги та недоліки розглянутих моделей прогнозування та їх модифікацій, удосконалено модель прогнозування геопросторових даних в системах обробки геопросторової інформації.

Мета статті - розробка моделі прогнозування геопросторових даних для прогнозування та прийняття обгрунтованих та оптимальних управлінських рішень в системах обробки геопросторової інформації.

\section{Виклад основного матеріалу}

Модель часової динаміки геопросторових даних базується на узагальненій моделі стаціонарного випадкового процесу [8]. Випадковий процес називається стаціонарним, якщо в кожен момент часу $t$ випадковий розподіл значень випадкової величини $X_{t}$ залежить тільки від іiі попередніх значень і відстані по часу до них, але не від самих значень часу:

$$
X_{t}=c+\sum_{i=1}^{p} a_{i} X_{t-i}+\varepsilon_{t},
$$

де $c$ - деяка константа, не втрачаючи загальності можна прийняти, що $c=0$;

$a_{i}$ - коефіцієнти моделі;

$p$ - порядок моделі;

$\varepsilon_{t}$ - білий шум з дисперсією $\sigma^{2}$, що згенеровано в той самий момент часу $t$.

В такому випадку кажуть, що задана модель $\mathrm{AR}(\mathrm{p})$ - авторегресія порядку $p$ [9-10].

Модель $\mathrm{MA}(q)$ ковзного середнього порядку $q$ задається рівнянням [9-10]:

$$
X_{t}=\mu+\sum_{i=1}^{q} b_{i} \varepsilon_{t-i}+\varepsilon_{t},
$$


де $\mu \epsilon$ математичним сподіванням $X_{t}$ i також можна прийняти, що $\mu=0$.

Узагальнена модель авторегресії-ковзного середнього $\operatorname{ARMA}(p, q) \epsilon$ об'єднанням моделей авторегресії $\mathrm{AR}(\mathrm{p})$ та ковзного середнього MA(q) і задається рівнянням [9-11]:

$$
X_{t}=c+\sum_{i=1}^{p} a_{i} X_{t-i}+\sum_{i=1}^{q} b_{i} \varepsilon_{t-i}+\varepsilon_{t},
$$

де збережено всі попередні позначення.

Якщо процес $є X_{t}$ не є стаціонарним, то доцільно розглянути $\Delta^{d} X_{t}$ - різниці порядку $d$.

Часовий ряд називається інтегрованим порядку $d$, якщо різниці ряду порядку $d \in$ стаціонарними [9]. В такому випадку доцільно використовувати модель інтегровану модель авторегресії-ковзного середнього $\operatorname{ARIMA}(p, d, q)$, яка є узагальненням моделі $\operatorname{ARMA}(p, q)$ для різниць ряду $\Delta^{d} X_{t}$, тобто:

$$
\Delta^{d} X_{t}=c+\sum_{i=1}^{p} a_{i} \Delta^{d} X_{t-i}+\sum_{i=1}^{q} b_{i} \varepsilon_{t-i}+\varepsilon_{t},
$$

Уніфікуючи виклад, зауважимо, що рівняння (4) можемо також представити в операторній формі (5):

$$
X_{t}=\hat{\boldsymbol{M}}(q) \hat{\boldsymbol{I}}(d) \hat{\boldsymbol{A}}(p) \hat{\boldsymbol{I}}^{-1}(d)\left\{X_{t-1}, X_{t-2}, \ldots\right\},
$$

де оператор $\hat{\boldsymbol{M}}(q)$ описує модель ковзного середнього МА(q) і задається рівнянням (2);

- оператор $\hat{A}(p)$ описує модель авторегресії $\mathrm{AR}(\mathrm{p})$ і задається рівнянням (1).

Введено інтегруючий оператор порядку $d$, такий, що обернений до нього $\hat{\boldsymbol{I}}^{-1}(d) \epsilon$ оператором різниці того самого порядку $\hat{\boldsymbol{I}}^{-1}(d)=\Delta^{d}$.

Схематично це представлено на рис. 1.

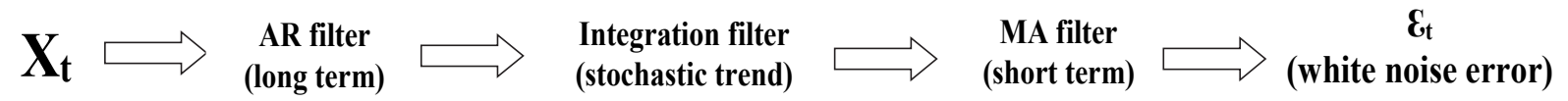

Рис. 1. Схематичне представлення моделі ARIMA

Джерело: розроблено авторами за даними [9].

Одним із недоліків моделі ARIMA $(p, d, q) \epsilon$ складність визначення порядку і параметрів моделі.

Підхід Бокса-Дженкінса [9] до аналізу часових рядів полягає в тому, що в першу чергу оцінюється стаціонарність ряду. Різними тестами виявляються наявність поодиноких коренів і порядок інтегрованості тимчасового ряду (зазвичай обмежуються першим або другим порядком).
Далі при необхідності (якщо порядок інтегрованості більше нуля) ряд перетворюється взяттям різниці відповідного порядку і вже для перетвореної моделі будується деяка ARMA-модель, оскільки передбачається, що отриманий процес є стаціонарним, на відміну від вихідного нестаціонарного процесу (різницевостаціонарного або інтегрованого процесу порядку $d$ ).

Схематично це представлено на рис. 2.

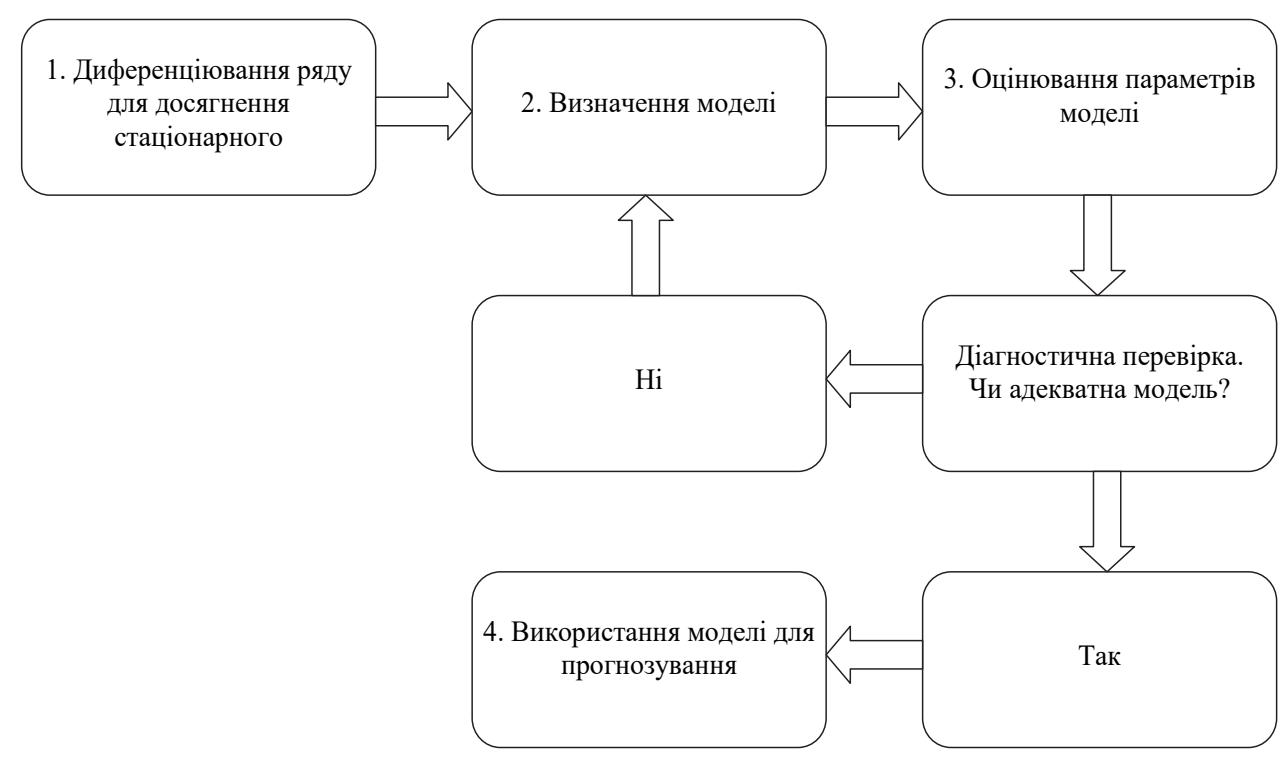

Рис. 2. Схематичне представлення підходу Бокса-Дженкінса до аналізу часових рядів Джерело: розроблено авторами за даними [9]. 
Таким чином, порядок різниці $d$ визначається 3 умови стаціонарності різниць ряду $\Delta^{d} X_{t}$. Пошук відповідних значень порядку моделі ARMA $p$ та $q$ в моделі $\operatorname{ARMA}(p, q)$ може бути полегшено шляхом побудови частинних автокореляційних функцій для оцінки $p$, а також використання автокореляційних функцій для оцінки $q$.

Броквел та Девіс [11] для пошуку $p$ i $q$ радять застосовувати інформаційний критерій Акаіке (IKA) [12].

Для моделі $\mathrm{AR}(p)$, якщо порядок задано $p$, то коефіцієнти моделі можна отримати за допомогою методу найменших квадратів, що призводить до відомої схеми Юла-Волкера $[9 ; 13]$ :

$$
a=\left(\begin{array}{cccccc}
1 & \rho_{1} & \rho_{2} & \rho_{3} & \ldots & \rho_{p-1} \\
\rho_{1} & 1 & \rho_{1} & \rho_{2} & \ldots & \rho_{p-2} \\
\rho_{2} & \rho_{1} & 1 & \rho_{1} & \ldots & \rho_{p-3} \\
\rho_{3} & \rho_{2} & \rho_{1} & 1 & \ldots & \rho_{p-4} \\
\ldots & \ldots & \ldots & \ldots & \ldots & \ldots \\
\rho_{p-1} & \rho_{p-2} & \rho_{p-3} & \rho_{p-4} & \ldots & 1
\end{array}\right)^{-1}\left(\begin{array}{c}
\rho_{1} \\
\rho_{2} \\
\rho_{3} \\
\ldots \\
\rho_{p-1} \\
\rho_{p}
\end{array}\right),
$$

де позначено $\rho_{i}-$ автокореляції (значення індексу $i=1,2, \ldots, p)$, що розраховуються як відношення (7):

$$
\rho_{i}=\frac{R_{i}}{R_{0}},
$$

i введено позначення для автоковаріації $R_{i}$, що розраховується з $N$ спостережень ряду $X_{t}$ :

$$
R_{i}=\frac{1}{N-i} \sum_{t=1}^{N} X_{t} X_{t-1}
$$

Параметри моделі MA(q) знаходяться методом найменших квадратів [13].

Для моделювання часової динаміки геопросторових даних пропонується використовувати адаптивну селективну модель на базі ансамбля моделей $\{\operatorname{ARIMA}(p, d, q)\}$ з заданими набором параметрів $\{p\},\{d\},\{q\}[14]$. Враховуючи неоднозначність вибору алгоритму селекції прогнозу [15], вибір оптимального прогнозу проводиться на основі статистичного аналізу отриманого ансамбля прогнозів $\left\{X_{t}\right\}$.

В якості процедури об'єднання прогнозів пропонується розбивати значення $\left\{X_{t}\right\}$ на кластери $\left\{X_{t}\right\}_{c}$ і для вихідного значення $\bar{X}_{t}$ брати середне по кластеру, для якого досягається оптимум (не втрачаючи загальності можна прийняти, що оптимум - це мінімум) за заданим критерієм $\theta\left(\left\{X_{t}\right\}_{c}\right)$ :

$$
\bar{X}_{t}=\left\langle\left\{X_{t}\right\}_{c=c_{0}}\right\rangle
$$

де

$$
c_{0}=\underset{c}{\arg \min } \theta\left(\left\{X_{t}\right\}_{c}\right),
$$

і використовуються трикутні дужки $\langle\ldots\rangle$ для позначення операції усереднення.

В якості критерія селекції $\theta\left(\left\{X_{t}\right\}_{c}\right)$ пропону- ється використовувати мінімум суми квадратів відхилень для $T$ попередніх прогнозів:

$$
c_{0}=\underset{c}{\arg \min } \sum_{t-T}^{t-1}\left(\left\{\bar{X}_{t}\right\}_{c}-\left\{X_{t}\right\}_{c}\right)^{2} .
$$

Таким чином, удосконалено модель прогнозування даних, яка представляє собою адаптивну селективну модель на базі ансамблю інтегрованих моделей авторегресії-ковзного середнього $\{\operatorname{ARIMA}(p, d, q)\}$ різних порядків, при цьому в якості критерія селекції використовується мінімум суми квадратів відхилень для попередніх прогнозів, що забезпечує точність та робастність прогнозу і дає можливість приймати на його основі обгрунтовані управлінські рішення.

\section{Висновки}

Таким чином, для прогнозування та прийняття обгрунтованих та оптимальних управлінських рішень в системах обробки геопросторової інформації на основі геопросторових даних запропоновано використовувати статистичні моделі.

Удосконалено модель прогнозування даних, яка, на відміну від відомих, представляє собою адаптивну селективну модель на базі ансамблю інтегрованих моделей авторегресії-ковзного середнього $\{\operatorname{ARIMA}(p, d, q)\}$ різних порядків. При цьому в якості критерія селекції використовується мінімум суми квадратів відхилень для попередніх прогнозів. Це, в свою чергу, забезпечуе точність та робастність прогнозу і дає можливість приймати на його основі обгрунтовані управлінські рішення.

Напрямком подальших досліджень $є$ оцінювання точності та обгрунтованості прогнозів, тобто проведення верифікації прогнозів. Оцінка якості отриманого прогнозу буде виконуватися з використанням сукупності критеріїв, процедур та способів. 


\section{Список літератури}

1. Next generation of GIS: must be easy / Z. A-Xing, Z. Fang-He, L. Peng, Q. Cheng-Zhi // Annals of GIS. -2021. - № 27. - P. 7186. https://doi.org/10.1080/19475683.2020.1766563.

2. Долгіх А.О. Аналіз методів, моделей та програмних засобів прогнозування часових рядів / А.О. Долгіх, О.Г. Байбуз // Открытые информационные и компьютерные интегрированные технологии. - 2018. - № 78. - С. $74-87$.

3. Jingfei Yang M.Sc. Power System Short-term Load Forecasting / M.Sc. Jingfei Yang. - Darmstadt: Elektrotechnik und Informationstechnik der Technischen Universitat, 2006. - 139 p.

4. Autoregressive conditional heteroskedasticity [Electronic resource]. - Available at: https://en.wikipedia.org/ wiki/Autoregressive_conditional_heteroskedasticity.

5. Нейронні мережі [Електронний ресурс]. - Режим доступу: http://www.aiportal.ru/articles/neural-networks/neuralnetworks.html.

6. Лук'яненко I.Г. Аналіз часових рядів. Побудова моделей ARIMA, ARCH/GARCH з використанням пакета E.Views 6.0, Ч. 1 / І.Г. Лук'яненко, В.М. Жук. - К.: Аграр Медіа Груп, 3013. - 187 с.

7. Hyndman R.J. Forecasting: Principles and Practice / R.J. Hyndman, G. Athanasopoulos. - Melbourne: Monash University, 2018. $-328 \mathrm{p}$.

8. Shumway R.H. Time series analysis and its applications: with R examples / R.H. Shumway, D.S. Stoffer. - Springer: Springer, 2010. $-596 \mathrm{p}$.

9. Time Series Analysis: Forecasting and Control / G.E.P. Box, G.M. Jenkins, G.C. Reinsel, G.M. Ljung. - Hoboken: Prentice Hall, 2016. - 705 p.

10. Enders W. Stationary Time-Series Models / W. Enders. - New York: Wiley, 2004. - 48 p.

11. Brockwell P.J. Time Series: Theory and Methods / P.J. Brockwell, R.A. Davis. - New York: Springer, 2009. - 273 p.

12. Akaike H. Information theory and an extension of the maximum likelihood principle / H. Akaike, B. Petrov, F. Csáki. Budapest: Akadémiai Kiadó, 1973. - 267 p.

13. Мокін О.Б. Метод ідентифікації моделі авторегресії-ковзного середнього АРКС (p,q) з довільними значеннями порядків p, q, який узагальнює методику Юла-Уокера [Електронний ресурс] / О.Б. Мокін, В.Б. Мокін, Б.І. Мокін // Наукові праці Вінницького національного технічного університету. - 2014. - № 2. - Режим доступу: http://nbuv.gov.ua/UJRN/VNTUV_2014_2_11.

14. Лукашин Ю.П. Адаптивные методы краткосрочного прогнозирования временных рядов / Ю.П. Лукашин. - М.: Финансы и статистика, 2003. - 416 с.

15. Васильев А.А. Генезис гибридных моделей прогнозирования на основе объединения прогнозов / А.А. Васильев // Вестник Тверского государственного университета. - 2014. - № 1. - С. 316-331.

Надійшла до редколегї 01.03.2021

Схвалена до друку 12.05.2021

\section{Відомості про авторів:}

\section{Худов Геннадій Володимирович} доктор технічних наук професор начальник кафедри

Харківського національного університету

Повітряних Сил ім. І. Кожедуба,

Харків, Україна

https://orcid.org/0000-0002-3311-2848

\author{
Маковейчук Олександр Миколайович \\ доктор технічних наук \\ провідний науковий співробітник \\ Харківського національного університету \\ радіоелектроніки, \\ Харків, Україна \\ https://orcid.org/0000-0003-4425-016X
}

\section{Бутко Ігор Миколайович}

кандидат технічних наук доцент заступник генерального директора

ДП “Центр державного земельного кадастру”, Київ, Україна

https://orcid.org/0000-0002-2859-0351

\section{Information about the authors:}

\author{
Hennadii Khudov \\ Doctor of Technical Sciences Professor \\ Head of Department \\ of Ivan Kozhedub Kharkiv \\ National Air Force University, \\ Kharkiv, Ukraine \\ https://orcid.org/0000-0002-3311-2848
}

Oleksandr Makoveychuk

Doctor of Technical Sciences

Lead Research

of Kharkiv National University

of Radio Electronics,

Kharkiv, Ukraine

https://orcid.org/0000-0003-4425-016X

\author{
Ihor Butko \\ Candidate of Technical Sciences Associate Professor \\ Deputy General Director \\ of SE "State Land Cadaster", \\ Kyiv, Ukraine \\ https://orcid.org/0000-0002-2859-0351
}


Хижняк Ірина Анатоліївна

кандидат технічних наук

провідний науковий співробітник

Харківського національного університету

Повітряних Сил ім. І. Кожедуба,

Харків, Україна

https://orcid.org/0000-0003-3431-7631
Irina Khizhnyak

Candidate of Technical Sciences

Lead Research

of Ivan Kozhedub Kharkiv

National Air Force University,

Kharkiv, Ukraine

https://orcid.org/0000-0003-3431-7631

\section{МОДЕЛЬ ПРОГНОЗИРОВАНИЯ ГЕОПРОСТРАНСТВЕННЫХ ДАННЫХ В СИСТЕМАХ ОБРАБОТКИ ГЕОПРОСТРАНСТВЕННОЙ ИНФОРМАЦИИ}

Г.В. Худов, А.Н. Маковейчук, И.Н. Бутко, И.А. Хижняк

Предметом исследования в статье является прогнозирование геопространственных данных в системах обработки геопространственной информации. Целью статьи является разработка модели прогнозирования геопространственных данных в системах обработки геопространственной информации. Усовершенствована модель прогнозирования данных, которая представляет собой адаптивную селективную модель на базе ансамбля интегрированных моделей авторегрессии-скользящего среднего \{ARIMA $(p, d, q)\}$ различных порядков. При этом в качестве критерия селекции используется минимум суммы квадратов отклонений для предыдущих прогнозов, обеспечивает точность и робастность прогноза и дает возможность принимать на его основе обоснованные управленческие решения. Направлением дальнейших исследований является проведение верификаиии полученного прогноза.

Ключевые слова: геопространственные данные, обработка геопространственной информации, модель прогнозирования, ARIMA модель, АRMA модель, временной ряд.

\section{A MODEL FOR PREDICTION OF GEOSPATIAL DATA IN SYSTEMS FOR PROCESSING GEOSPATIAL INFORMATION}

\section{H. Khudov, O. Makoveychuk, I. Butko, I. Khizhnyak}

The subject of research in the article is the forecasting of geospatial data in geospatial information processing systems. The goal of the article is to develop a model for predicting geospatial data for forecasting and making sound and optimal management decisions in geospatial information processing systems. It has been established that the statistical analysis of data is an obligatory stage of the management system at all its levels. The models for forecasting time series are considered, which are divided into two groups, namely, subject area models and time series models. Their advantages and disadvantages are established. Selected statistical models for forecasting time series, which include regression models, autoregressive models, models based on exponential smoothing and others. A class of algorithms for forecasting ARIMA time series is proposed, well-known modifications of ARIMA models are given. The Box-Jenkins approach to the analysis of time series is described, a schematic representation of the ARIMA model is given, a schematic representation of the Box-Jenkins approach to the analysis of time series. The data prediction model is improved, which is an adaptive selective model based on an ensemble of integrated autoregressive moving average models \{ARIMA $(p, d, q)\}$ of various orders. At the same time, the minimum of the sum of squares of deviations for previous forecasts is used as a selection criterion, ensures the accuracy and robustness of the forecast and makes it possible to make informed management decisions on its basis. The direction of further research is to assess the accuracy and validity of forecasts, i.e. verification of forecasts. The assessment of the quality of the resulting forecast will be carried out using a set of criteria, procedures and methods.

Keywords: geospatial data, geospatial information processing, forecasting model, ARIMA model, ARMA model, time series. 